\title{
ANAESTHESIA FOR ABDOMINAL EMERGENCIES IN CHILDREN*
}

\author{
T. J. MaCaughex, M.B., B.CH., D.A. $†$
}

EMERGENCY SURGERY in infants and children makes special demands on the anaesthetist. This is so because of three interacting factors: the child's condition, the hospital environment during the emergency hours of evening and night, and the nature of the surgery. This discussion is confined to anaesthesia for abdominal emergencies.

\section{General Considerations}

\section{The Child}

The term "emergency" is a relative one, and in the case of acute abdominal conditions there is always time for adequate preparation. Surgery should be postponed until severe shock and dehydration have been overcome. It may, be impossible or impracticable to restore Huid and electrolyte balance to normal in the face of the pathology present: this is not the object of therapy. A balance has to be struck between the diminishing returns of preparation and the gains and risks of operative intervention and anaesthesia. Before even an appendectomy it has traditionally been regarded as necessary to correct pyrexia of $102^{\circ} \mathrm{F}$. or more, or ketonuria, and the wisdom of this is unquestioned.

In some cases compatible blood should be given preoperatively or made available for surgery. Its use is indicated preoperatively where blood loss or gross malnutrition are known or suspected; for example, a non-penetrating abdominal injury involving a ruptured spleen, a bleeding ulcer in a Meckel's diverticulum, or a long-standing pyloric stenosis. During surgery blood should be on hand where a bowel resection is possible, as in 'an intussusception of several days' standing.

Infants need special consideration. The loss of $2 \mathrm{C} \mathrm{ml}$. blood in a new-born is equal to the loss of about a pint in an adult. Where tissue dissection and handling of bowel is likely to be fairly prolonged, as it is in most abdominal operations in infants, except pyloromyotomy, blood should be available. Surgery should not commence till a vein has been secured. Almost invariably this must be done by cut-down.

These children are either very frightened or too sick to care. Their predicament is such that they must often be denied the more pleasant induction techniques of anaesthesia. Special care must be taken to treat then with the utmost gentleness.

\section{The Hospital Environment}

This is not the same at 2:00 a.m., for example, as at 9:00 a.m. Hospital wards usually have considerably fewer nurses on duty in the evening and at night than

*Presented at the Annual Meeting of the Canadian Medical Association, Toronto, June, 1963. tAnaesthetist-in-Chief, The Children's Hospital, and Assistant Professor of Surgery (Anaesthesia), University of Manitoba, Winnipeg, Manitoba. 
during the day. The institution of a recovery room in a hospital removes the necessity for, and therefore the existence of, a high standard of care on the wards for the immediate post-anaesthetic period, If the recovery room is closed during the evening-and emergencies may be so few as to appear Ito justify this -then children will have to be returned to the ward where, paradoxically, the standard of care will be lower than before the setting up of a recovery room. In addition, fatigue may tempt personnel to take short-cuts in patient care which would be unthinkable during the usual operating hours.

One slight advantage is occasionally evident: there is less pressure of the next case on the list to consider, as sometimes happens during elective surgery. The energy and attention of the whole team can be brought to bear on the problem at hand, without distractions.

All these factors will have to be taken into account; an anaesthetic technique acceptable at 10:00 a.m. may not be advisable at 3:00 a.m. for the same operation.

The customs, experience, and training of the department of anaesthersia in each hospital will determine the best techniques and practices for that institution. One should never attempt anything novel or different when faced with an emergency. The methods described are those we have found most satisfactory: ours is a teaching hospital of 230 beds, drawing on a total population of about one million, with four staff anaesthetists and two trainees continually giving paediatric anaesthesia.

\section{Operator and Operation}

The skill and experience of the surgeon with children count here. Speed and gentleness in tissue handling are important: anyone knows this, who has watched an otherwise good surgeon, lacking experience in children, handle the gut, for example, in a patient with congenital diaphragmatic hernia obr a malrotation. A new-born can be lifted clear off the table with a finger or two under the rectus abdominis by a surgeon who is more accustomed to doing gall bladder surgery in fat adults.

Emergency surgery in infants is not for the general practitioner, and ideally not for the general surgeon either, unless he has had definite training and experience in it. Even in larger children, the commonest emergency, acute appendicitis, may prove to be unpredictably difficult.

Surgeons who have had little experience with children will be unaware of the importance of preoperative assessment and fluid therapy, of what constitutes a major blood loss in proportion to the child's blood volume, and of what regime to follow postoperatively regarding the need for and amount of intravenous fluids. The paediatric anaesthetist will have to know and advise.

The nature of the operation will modify the anaesthetic technique. Muscle relaxants are commonly employed with good effect for abdominal surgery in adults. There has been some reluctance to "employ them in infants and children. Abdominal surgery is greatly helped by their judicious use even in infants. The diaphragm is powerful in the new-born, being the chief muscle of respiration. During spontaneous respiration its movements may extrude the intestines and hinder abdominal closure. A proper knowledge of the use of muscle relaxants is just as important in infants and children as in adults. 


\section{Anaesthetic Technique}

\section{General Considerations}

\section{Preoperative Preparation}

The anaesthetist will check on the adequacy of the preoperative investigation and preparation. Generally speaking, for emergency abdominal surgery in the neonate and small infant, compatible blood should be on hand. A rough but useful guide is to calculate on a total blood volume of $40 \mathrm{ml}$./1b. body weight. This figure in a new-born is usually about $300 \mathrm{ml}$., although whether or not the cord was stripped before tying at birth will make a significant difference. Usually 100 to $150 \mathrm{ml}$. blood is a generous amount to have ready before surgery.

\section{When to Operate}

It is customary at some hospitals for the department of anaesthesia to request postponement of some "emergency" operations, where feasible, for six to eight hours following ingestion of fluid or food. This is desirable, for example, in the case of a Colles' fracture where general anaesthesia is deemed necessary. Luckily, most children and infants coming for emergency abdominal surgery do not present such a problem. For example, children who come for emergency appendectomy seldom have undigested food in their stomachs, as anorexia appears very early in the course of the disease. A history of having recently eaten and retained a good meal raises doubts that the diagnosis is a good one, although, in a child, it may be. In such cases, a resolute attempt must be made to empty the stomach by inducing vomiting through the passage of a wide-bore stomach tube, and by gastric lavage. Aspiration of vomitus during anaesthesia is attended with lethal possibilities. Good judgment is needed: if there is a history of drunking some fluids two or three hours before the contemplated surgery, then passage of a gastric suction tube often causes a sick child to become more upset than it is worth; however, it would be unreasonable to delay removal of a probably gangrenous appendix, or the operative reduction of an intussusception of dangerously long standing, in order to satisfy the ritual six hours. One does not necessarily accept, without discussion, the hour for operation specified by the surgeon. The anaesthetist must weigh all the factors in order to bring the patient maximum benefit and safety. He will do wrong, if, in any degree, an overzealous and false desire to "wait and play safe" is allowed free rein in the face of fulminating pathology.

Surgery and anaesthesia in a dehydrated patient with marked derangement of electrolyte and acid-base balance can cause rapid deterioration. Surgery should not, however, be delayed in every case until normal electrolyte balance has been restored. The purpose of preparation is to set the bødy's compensatory powers, especially those of the kidney, on the path of restoring normality. Surgery must be a decisive step, a turning point for the better for the patient; anaesthesia should cause the least possible interruption of these natural recovery powers. In practical terms for the anaesthetist, this means the avoidance of metabolic acidosis from hypoxia or overly deep anaesthesia, and respiratory acidosis due to alveolar hypoventilation; light anaesthesia with controlled respiration is the essence of the technique. 


\section{Preanaesthetic Medication and Induction of Anaesthesia}

Atropine only is given one hour prior to surgery. The usual dose we employ varies from $0.2 \mathrm{mg}$. for a neonate to $0.6 \mathrm{mg}$. for a 10 - to 12 -year-old child, given intramuscularly. If the body temperature is $101^{\circ} \mathrm{F}$. or more the dose is slightly reduced. It is well known that this premedication is quite ineffective in protecting against vagal reflexes. This has been demonstrated, for example, in the case of an adolescent girl, when the injection of $0.6 \mathrm{mg}$. atropine intramuscularly before surgery, and a further dose of $0.4 \mathrm{mg}$. given intravenously at the beginning of anaesthesia, were found to afford incomplete protection against succinylcholine bradycardia. ${ }^{1}$ Such vagal reflexes are generally innocuous if anaesthesia is otherwise well conducted and the cardiovascular system is normal. It is primarily for its drying effect on secretions that atropine is given here. This is especially valuable in small children when induction with an inhalation agent is usually advisable.

Before the anaesthetic is begun in the operating room, one should be sure to inspect the patient's abdomen: gross distension will put the anaesthetist very much on the "qui vive." Omission of this simple step has led to fatal results, as the sesult of unexpected regurgitation during induction.

No rectal thiopental is given to smaller children; the objective, as in omitting narcotics from the preoperative medication, is to secure as rapid an awakening from anaesthesia as possible. Ustually children of school age or over will co-operate for one attempt at least at venepuncture. They are given a small dose of intravenous thiopental, only two-thirds to three-quarters of the usual dose, which is $1 \mathrm{ml}$. of $2 \frac{12}{2}$ per cent solution or $25 \mathrm{mg}$. per year of age.

Smaller children and infants are induced with cyclopropane. While the infant is unaware of his predicament and can be gently put to sleep without any great protest, the two- or three-year-old is sometimes on the verge of panic. When very sick and toxic he will lie quietly indifferent, and the anaesthetist will note this. However, the child with an irreducible inguinal hernia, for example, or an intussusception, or even an acute appendicitis, will sometimes come to the operating room in a state bordering on terror. The anaesthetist must then form a temporary alliance with'the circulating nurse: between them they must provide the child, just for a few minutes, with what hè needs desperately, familiar landmarks of affection in a nightmarish landscape (Fig. 1). It is possible to induce the child quite quickly in the nurse's alms (Fig. 2). The tubing can be concealed between one's fingers and no face mask used. A very few breaths of 40 to 50 per cent cyclopropane with oxygen are all that are needed. The child can then be swiftly laid on the table and anaesthesia continued with face mask or as otherwise indicated.

As in the case of anaesthesia for emergency surgery'in adults, a wide-bore metal suction must be turned full on and available within reach, without having to lift one's eyes off the patient.

\section{Maintenance of Anaesțesia}

Endotracheal intubation is essential. By choice, in our hospital we do not use cuffed tubes, considering them traumatic and unnecessary. 


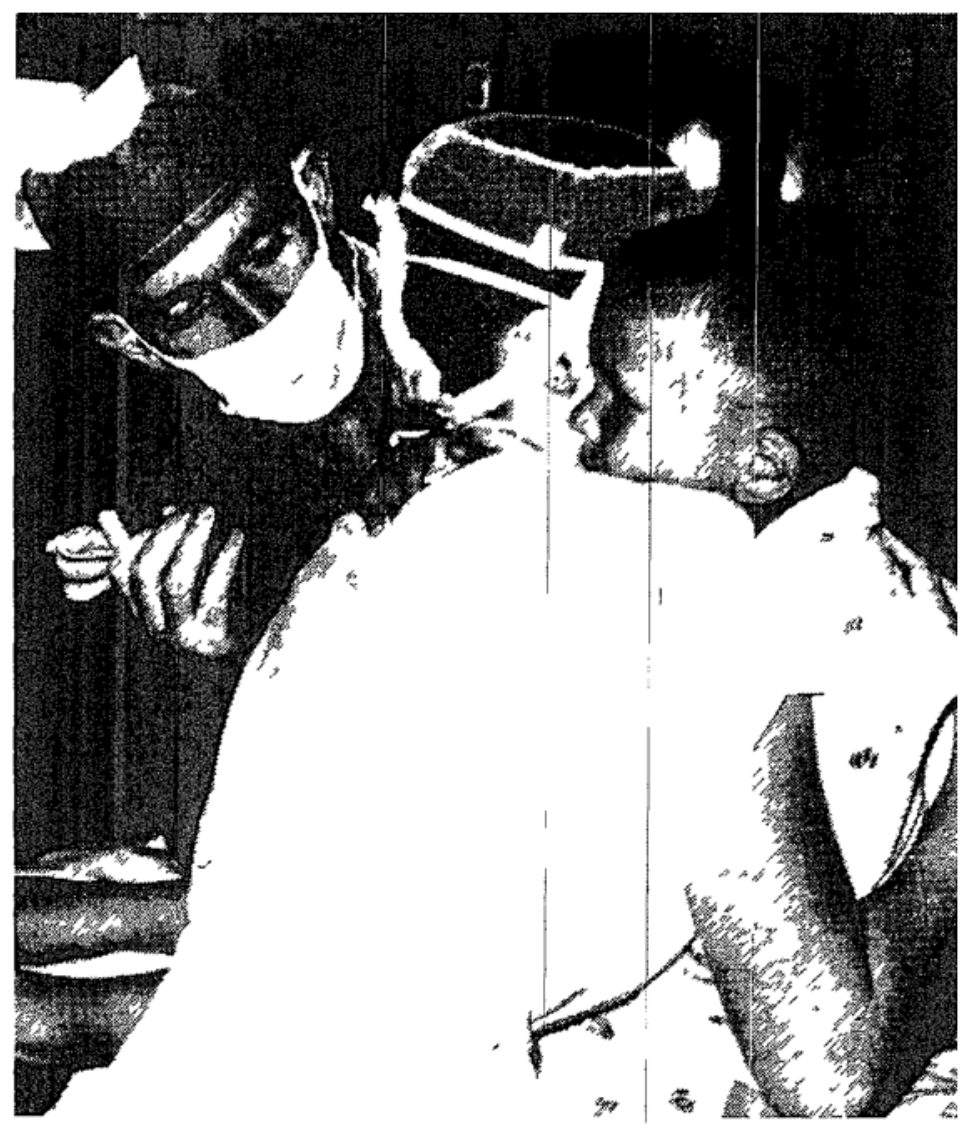

Figure 1

Aspiration of vomitus is always a major threat to life. During anaesthesia, to minimize the risk of regurgitation and to permit the drainage of the considerable quantities of saliva which always accumulate, the head of the infant or child is kept in the lateral position (Fig. 3).

Resistance to breathing is increased by the endotracheal tube, very markedly so in infants. Controlled respiration is necessary in most cases of emergency abdominal surgery.

\section{Muscle Relaxants}

There are four main advantages, then, to be gained from the use of muscle relaxants and controlled respiration:

1. The increased resistance to respiration is no longer important. The extra work of breathing which it would entail, especially in infants, is removed or minimized.

2. Alveolar hyperventilation is assured.

3. The use of muscle relaxants permits surgery to be done better and with less effort on the part of the surgeon, and with less trauma to delicate tissues.

4. Very light anaesthesia is possible: the advantages of this are many: rapid recovery of protective reflexes, minimal metabolic acidosis, quick return to 


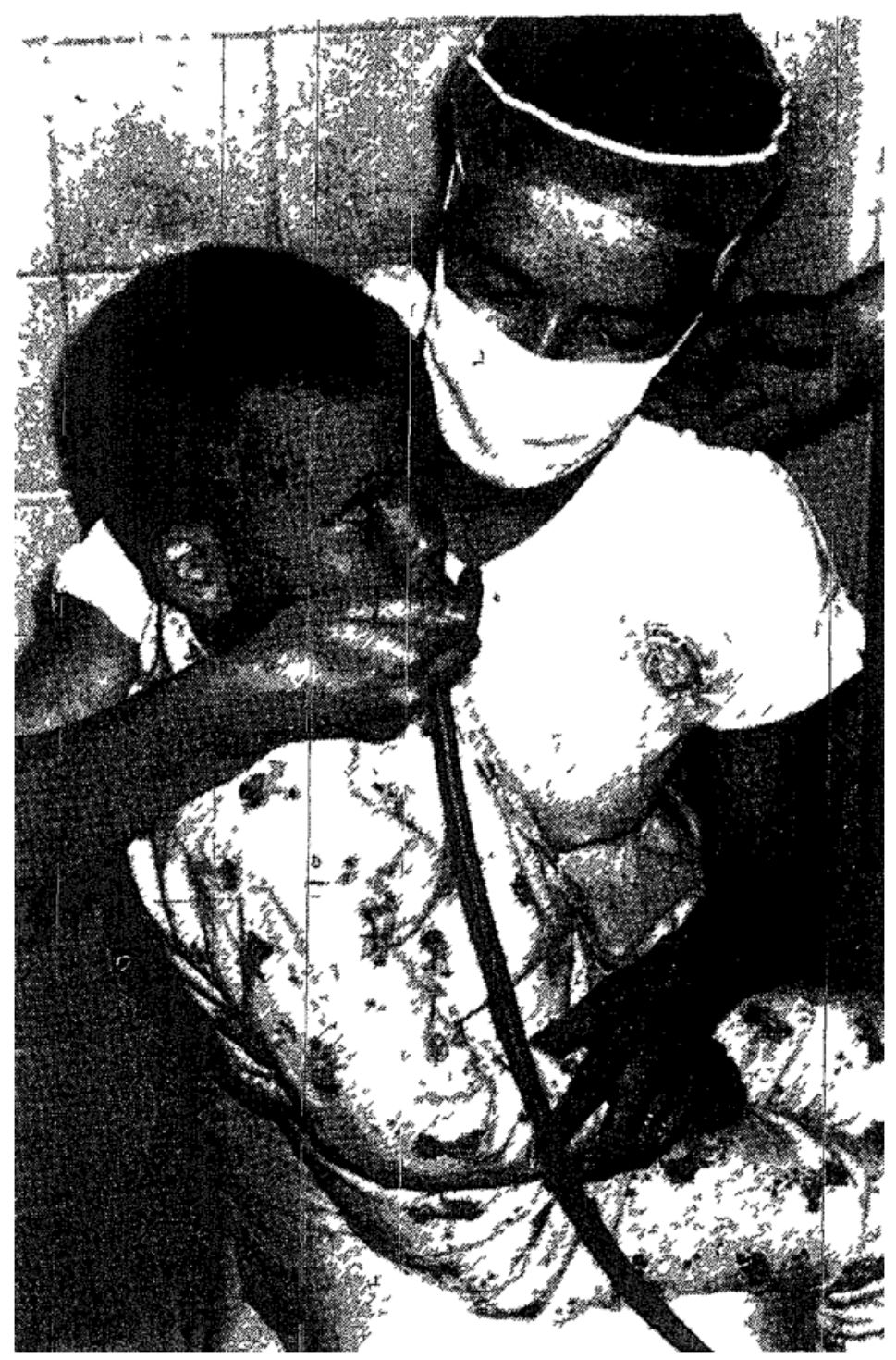

Figure 2

function of the body's homoeostatic acid-base mechanisms, especially those of the kidneys.

\section{Technique and Dosage}

This has been previously described for succinylcholine, the relaxant of choice. ${ }^{1}$ The drug is almost invariably given intravenously by intermittent dosage, and never by contmuous intravenous drip, which always results in some overdosage. Much smaller total doses are required than has been appreciated: an injection of $1 \mathrm{mg} / 3-4 \mathrm{lb}$. body weight enables endotracheal intubation to be done, and intermittent doses of $1 \mathrm{mg} . / 6-8 \mathrm{lb}$. body weight will last 2-5 minutes, ${ }^{3}$ depending on the depth of anaesthesia. Judgment of both the surgeon and the operation count for a good deal. An appendectomy can often be done with three injections of succinylcholine-one for endotracheal intubation, one as the peritoneum is 
opened, to facilitate exploration, and the third to make for easy elosure. A similar pattern can be used when a fast surgeon is doing a pyloromyotomy.

A record of dose and duration of action is kept on a piece of paper or even a wide strip of adhesive stuck on the head of the table; both hands are engaged and they must never have to fumble around for an anaesthetic.record at this period (Fig. 3). Memory is fickle, and one is continually being distracted by other things. This written record of doses and timing is carefully put on the

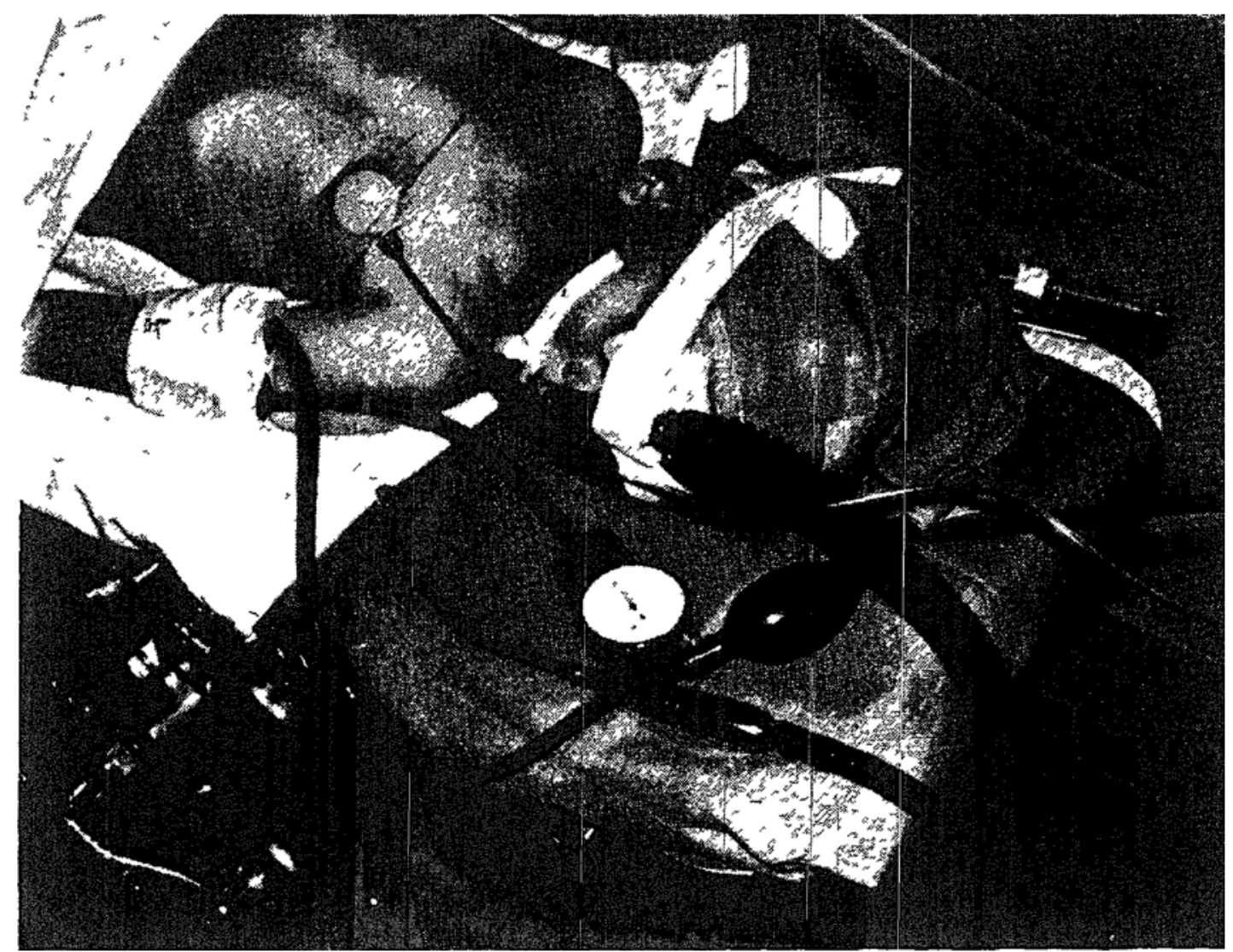

Figure 3

anaesthetic chart afterwards and the total figure noted. One has not been able to demonstrate that infants are any more resistant to succinylcholine than larger children, although this has been authoritatively stated. To what degree halothane, the anaesthetic agent used, and alveolar hyperventilation reduce the need for muscle relaxants as not been worked out, but without doubt they do contribute to the ease of controlling respiration.

The indication for giving more succinylcholine in the larger child is the first sign of the return of spontaneous breathing. In the infant, lightly anaesthetized, the return of muscle tone in the tongue, felt with the index finger, is an extremely useful sign. Generally, no more succinylcholine is given from the time of the peritoneal closure; from this point on, everything is geared to having the child as awake as possible just after the dressing has been applied to the incision. 


\section{Extended Action of Succinylcholine}

The duration of muscle relaxant action of succinylcholine is related to the type of pseudocholinesterase present in the subject's plasma. $\mathrm{It}_{1}$ is now realized that genetic factors determine the pattern of these pseudocholinesterases; recent work shows that there are three main genotypes, recognition of which depends on biochemical tests, such as the assessment of the dibucaine and fluoride numbers, but that more complex mechanisms also exist and await analysis. The inheritance of these types of pseudocholinesterase imitates very closely that of sickle-cell anaemia. ${ }^{2}$ Apparently about 2.8 per cent of the population can be expected to be heterozygous and about 1 in 3000 will be homozygous for an abnormal type of pseudocholinesterase, and therefore sensitive to succinylcholine. Extended action of succinylcholine has been rarely described in children and is almost unknown, according to the literature, in infancy. However, it seems reasonable to suppose that, since the same genetic pattern will exist throughout life, infants would also exhibit sensitivity; the fact that so few cases have been reported does" not outrule the possibility. Even in a children's hospital not many infants come to surgery. Of the number of anaésthetists doing this sort of work exclusively, relatively few may use intravenous succinylcholine very frequently-they may use it mostly intramuscularly. We have been using the technique of intermittent, intravenous succinylcholine for more than six years. So far we have not encountered a case of extended action'in an, infant, but then the total number 'of cases, when one is expecting an incidence of 1:3000, is numerically minute. The importance of using the minimum effective dose, as described in the section on dosage, is clear: some of these abnormal patterns show up as a moderate degree of sensitivity only; they would be immediately detected by a carefully kept dose-to-dose record. If the minimum doses were not given, or if a drip were used, gross overdosage would be inevitable. The only treatment for a case showing sensitivity is to continue to ventilate the patient adequately by intermittent positive pressure with oxygen until normal respiration has returned:

\section{The Use of Halothane}

Halothane is given in concentration of 0.25 to 1.25 per cent, with oxygen only. There have been recent reports of hepatic necrosis following its use..$^{3,4,5}$ Opinion is divided as to whether these accounts are unduly alarmist. The drug should not be used in the presence of liver disease, manifest or suspected.

The percentage vaporizer commonly employed (Fluotec) can give a false sense of security when respiration is controlled. The volume of halothane vapour going into solution in the alveolar capillaries and therefore carried by the blood to the tisşues depends on the percentage of the vapour in the inspired mixture, and other factors; it varies with the total functioning alveolo-capillary interface or the amount of alveolar ventilation (ignoring possibly uneven perfusion) in proportion to body mass. This factor, inasmuch as it is affected by the volume of ventilation, is varied by the anaesthetist: this surely helps to explain the apparently prolonged effect of halothane, given by controlled respiration, even when small percentages.on the vaporizer are used in a non-rebreathing technique. In addition, the back-up in the vaporizer during the periods of positive pressure can 
cause a momentary pick-up of large quantities of halothane. For these reasons we prefer to use halothane intermittently rather than continuously, especially in infants; 0.25 to 1.25 per cent is used in periods alternating with 50 per cent nitrous oxide and oxygen. Many good paediatric anaesthetists use only nitrous oxide or even control respiration in infants with oxygen only, on the grounds that the infant cannot feel pain: the piercing screams of an infant, a week or so of age, while being circumcised without anaesthesia give the lie to this. The celebrated pictures of the cellular structure of the cerebral cortex of the new-born cast some doubt, perhaps, on his intellectual prowess at that age, but not necessarily on his ability to feel pain.

\section{Monitoring}

Durnng anaesthesia the heart and breath sounds are continually monitored by precordial stethescope; careful fixing with water-proof adhesive will prevent its being washed away by the most extensive and enthusiastic skin preparation, Blood pressure is taken frequently; small cuffs now avallable allow one to do

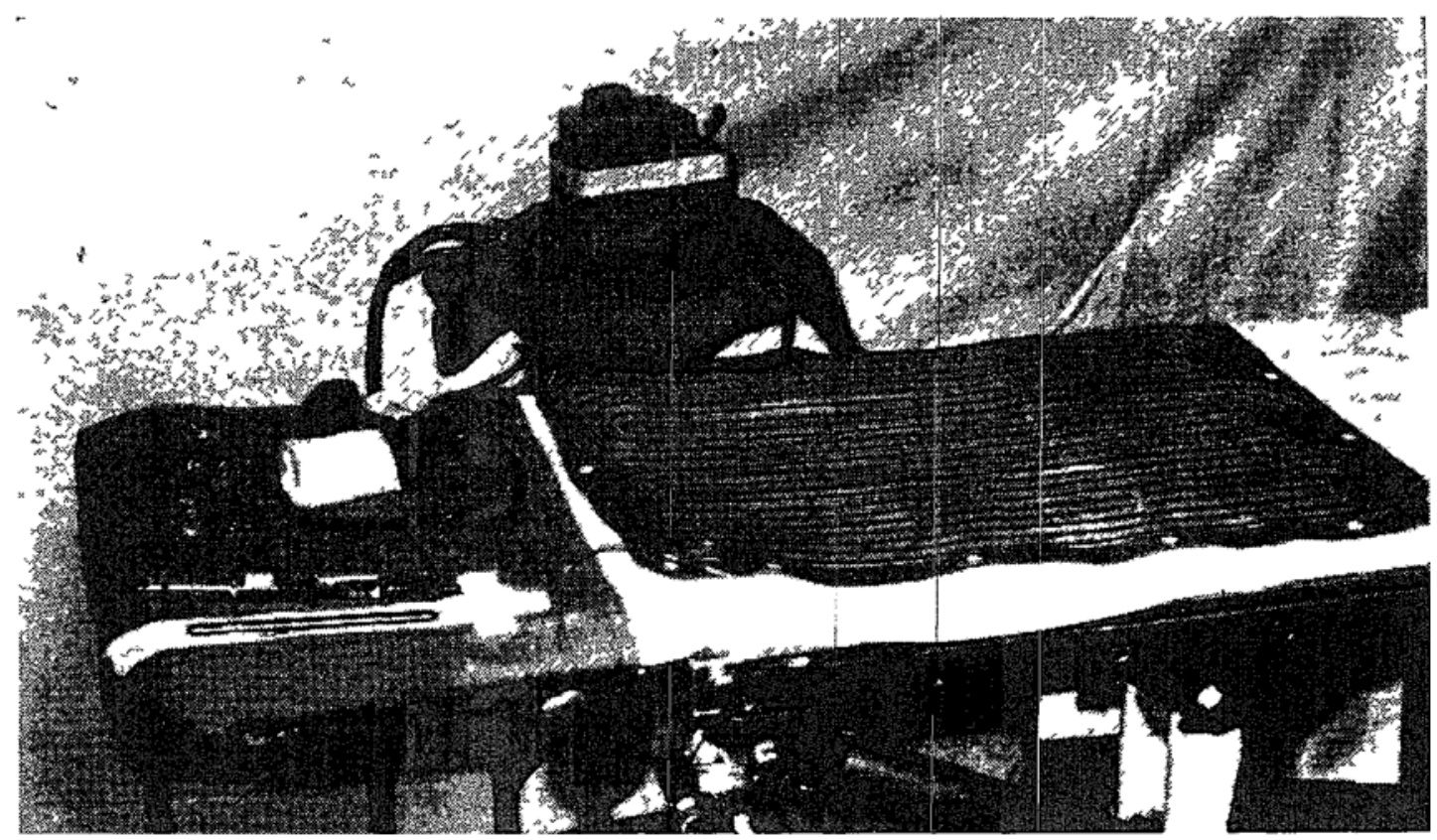

FIGURE 4

this even in infants. Body temperature must be kept from falling, as it will do when the work of respiration is removed and the child or infant exposed, often with loops of intestine losing heat and moisture, in air-conditioned operating rooms. To prevent this, the patient is placed on a plastic water mattress filled with warmed water which is circulated by a small electric motor (Fı. 4).

\section{Extubation}

Extubation is performed only when the child is almost awake. One must be sure as possible that vomiting has ended. 
The defensive reflex of coughing is so primitive that it sometimes takes precedence over vomiting, while the endotracheal tube is in place. The anaesthetist is thus lulled into believing that vomiting will not occur, and, because of the violent attempts to cough, he hastens to remove the tube; whereupon copious emesis enşues. This is an inconventent and embarrassing snare of nature; to avoud it the metal suction catheter is introduced into the mouth and the pharynx deliberately stimulated before extubation. The endotracheal tube is removed with the patient's head low in the lateral position; an airway prevents the tube from being bitten, a mouth gag must be to hand to pry the teeth apart if necessary (Fig. 5). The presence of the most active cough reflex is not enough to be sure that aspiration cannot occur. Spitting out is a voluntary action, and so extiusion of massive amounts of vomited matter from the mouth and pharynx is impossible if the patient is not conscious. Unless the anaesthetist is prompt to 1 emove such material, aspiration may ensue.

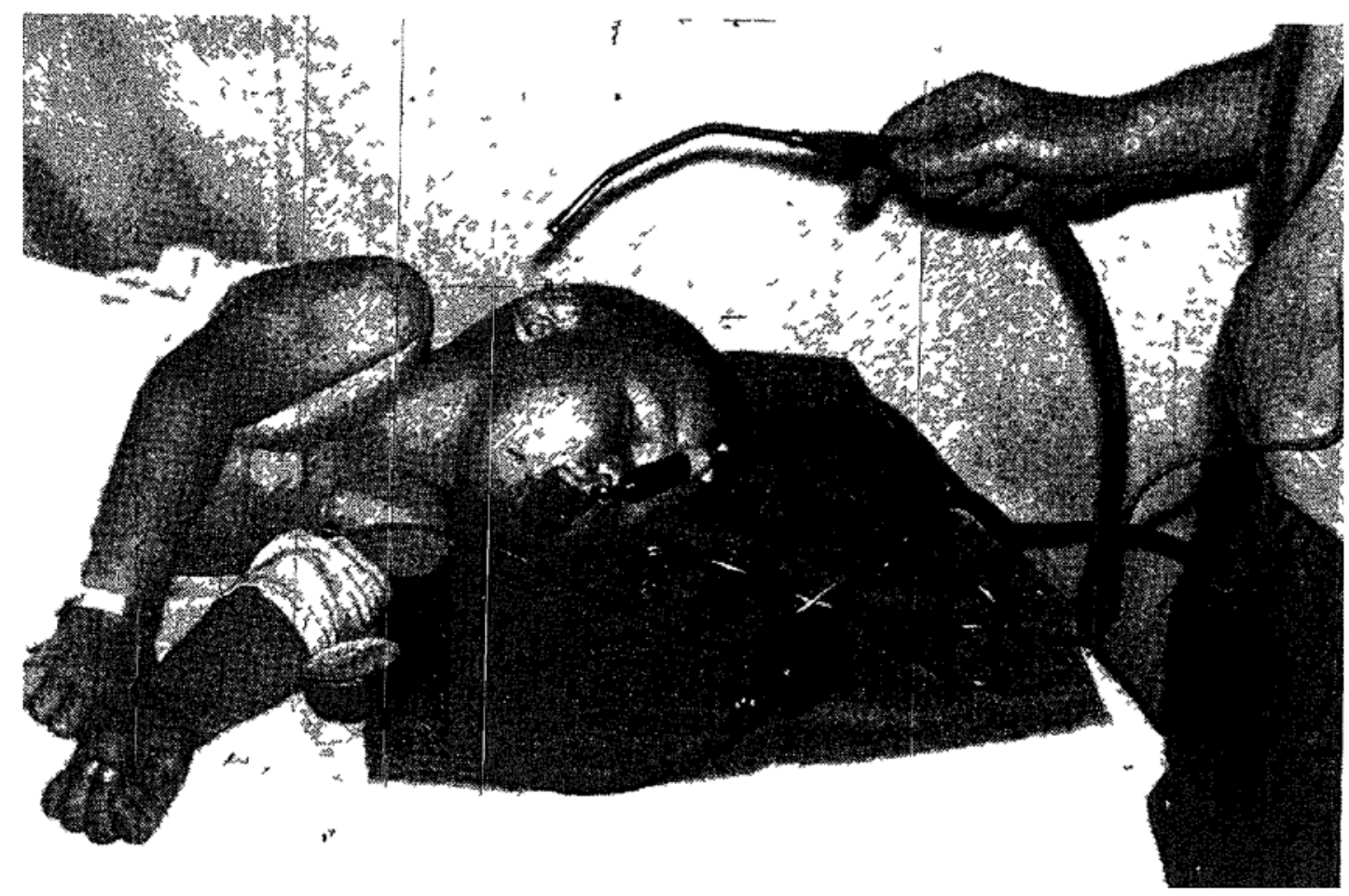

Figure 5

After extubation the chest is carefully auscultated. If the suspicion of aspiration of vomitus is confirmed by physical signs, bronchoscopy and washing out of the tracheobronchial tree must be done at once. Intravenous hydrocortisone (50-100 mg ) and antibiotic therapy will be needed postoperatively.

\section{In the New-born}

\section{Points of Special Interest}

Emergency surgery here is concerned with correction of congenital anomalies immediately endangering life. The neonate differs rather markedly from an 
infant even a few weeks old, and even more from an older child and adult. In the neonate about 80 per cent of the body weight is water compared with 60 per cent in the adult. While most of this fluid is intracellular in the adult, by far the greatest part of it is extracellular, and largely interstitial Aluid, in the new-born. Plasma volume is not expanded. The new-born can get along well for a few days after birth without lluids, and there is a considerable risk, with intravenous fluids, of overloading, because of the small total volumes involved.

In spite of the high haemoglobin and powerful heart in the new-born, blood loss is certainly not tolerated any better than in the adult. Most emergency abdominal procedures of any duration in the new-born involve a significant loss of blood, in contrast to adult surgery. The extensive tissue handling and manipulation involved in the correction of congenital deformities, even when carefully and skillfully performed, can cause a loss of $30 \mathrm{ml}$. of blood, or more. This corresponds to the loss of a pint in an adult, which surgeons accustomed to operating in adults seldom realize.

The normal new-born has relatively high chloride and low bicarbonate levels in the blood, which reflect a tendency to metabolic acidosis. The kidneys are apparently not well equipped to correct such tendencies. Concentrating 'power is low, a relatively high "urine obligatoire" being demanded, This is not as important in the neonate as the observation that serum carbonic anhydrase levels are far below those in adults. This enzyme, so central in manipulating hydrogen ions in the body cells, plays an important part in the bicarbonate mechanisms through which acid-base balance tends to be stabilized by the kidney, as well as in carriage and release of carbon dioxide in the red blood cells and in the lungs. Since the lungs in the new-born have not nearly the ventilatory reserve of those in the normal adult anyway, neither in proportion to body mass, nor when compared, mass for mass, as lung tissue, it is seen that respiratory acidosis might easily aggravate metabolic acidosis during general anaesthesia in the infant. This seems to us to reiterate the need for techniques, which perhaps have been more popular in adults, using light anaesthesia, with muscle relaxants removing the work of breathing and muscular activity completely, and permitting controlled respiration by intermittent positive pressure breathing. Alveolar hyperventilation is common and probably innocuous.

A cut-down for blood replacement is done in the operating room at the beginning of anaesthesia, generally at the ankle. By means of an extension and a three-way stopcock the anaesthetist can control this drip. In anaesthesia for the new-born the anaesthetist should take great pains to have everything available to his hands without lifting them from the head of the table (Fig. 3) where he should be seated. A drip is started momentarily to make sure that the vein is patent and is then turned off at the stopcock; the danger of overloading is too great in a neonate to keep a drip going merely to maintain a needle open, in the distracting atmosphere of the operating room. Blood and succinylcholine can be given through the three-way stopcock.

When the operative procedure is directed to correction of such abnormalities as duodenal atresia, malrotations, meconium ileus, and congenital perforations of the intestine, no anaesthetic problems needing further mention arise. The 
one stage pull-through operation for imperforate anus in the new-born is bloods and shocking Surgery for congental diaphragmatic herma and omphalocele creates special problems

Congental Diaphragmatic Heinia

Though commonly and perhaps properly considered a thoracic condition, in the common type of hernia through the foramen of Bochdalek, surgery is almost always done through the abdomen in the new-born period Most of the intestmes and some of the abdomnal viscera are frequently found in the

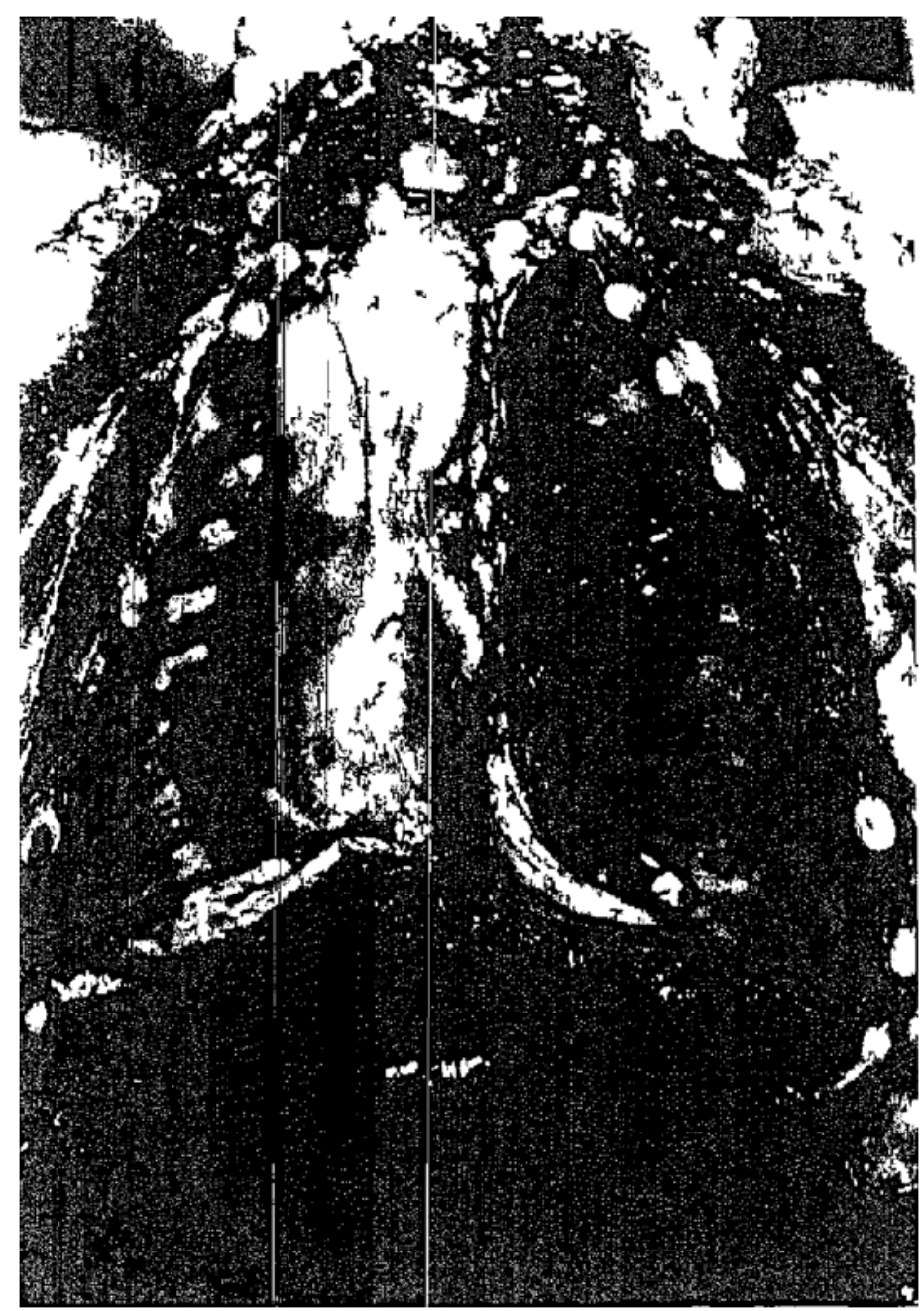

Figure 6

chest The Iung on the affected side (usually the left) is collapsed, and it mav be rudumentary and incapable of expansion when the abdommal contents are replaced in the belly The amaesthetist should not attempt too vigorously to expand this lung Such enthusiasm thas caused rupture of one or both lung, (Fig 6) If the lung is not foetal in type it will generally lave expanded by the thrrd or fourth postoperative dav 
A more uggent problem after repair of the diaphragmatic defect is peritoneal closure: the abdomen has never held, and is not capable of easily accommodating the viscera which are now packed into it. The use of muscle relaxants is fraught with danger here: the belly is completely relaxed, the peritoneum is tightly closed. The enormous pressure on the diaphragm, together with the fact that usually only one lung is functioning, makes spontaneous respiration precarious. Surgeon and anaesthetist must understand the problem. Thus a good effort is made to close the peritoneum without succinylcholine, using gauze packs, special retractors, or any other devices the surgeon may have. However, the handling of tissues and intestines is very considerable at best during this operation and with extremely difficult closure the bowel may become quite badly traumatized and haemorrhagic from continkous pushing and squeezing. In the double effect of good and ill from giving succinylcholine here, the benefit may outweigh the evil. A small dose of $1 \mathrm{mg} . / 6-8 \mathrm{lb}$. intravenously will facilitate extremely rapid, relatively easy, and markedly less traumatic closure. The patient at the end of this procedure must be as reactive as possible, without residual depression from anaesthesia or muscle relaxants and with blood loss adequately replaced. Even so, one may have to remain with the patient for a considerable period after the operation before spontaneous respiration is adequate.

\section{Omphalocele (Fig. 7)}

A similar problem exists here. In the extreme form, where no sac is present, the liver is outside the abdominal cavity, a plastic peritoneal reaction may be present, and the prognosis is poor. Even skin closure may be impossible. In lesser degrees, skin closure, with or without the help of a sheet of artificial material such as Teflon gauze, may be fairly easy and the abdomen will enlarge as the patient grows in size.

Here again muscle relaxants carry a distinct danger. Yet, for one thing, the use of very light anaesthesia is made possible only with them. Between the small doses of muscle relaxants, when spontaneous breathing has temporarily returned, the surgeon should be warned if respiration seems to be gravely hampered. In the more serious cases the surgeon usually has to compromise, complete skin closure being impossible.

\section{Pyloric Stenosis}

Strictly speaking, operative correction of pyloric stenosis is never an emergency. Intravenous fluids are given, when necessary, until electrolyte imbalance and metabolic alkalosis have been righted, even if this takes a matter of days. The infant who has not been diagnosed early and is below his birtli weight is an extreme example. In these cases hypoproteinaemia and anaemia usually dictate the use of blood preoperatively. The chronic alkalotic state should not be too hastily corrected. It is characterized by hypokalaemia with a shift of sodium from the extracellular fluid into the cell and a loss of intracellular potassium. Potassium must be given in addition to sodium and chloride. An effort to correct the hypokalaemia too rapidly, especially if kidney function is temporarily deranged, can lead to levels of circulating serum potassium dangerous to the cardiac rhythm. 


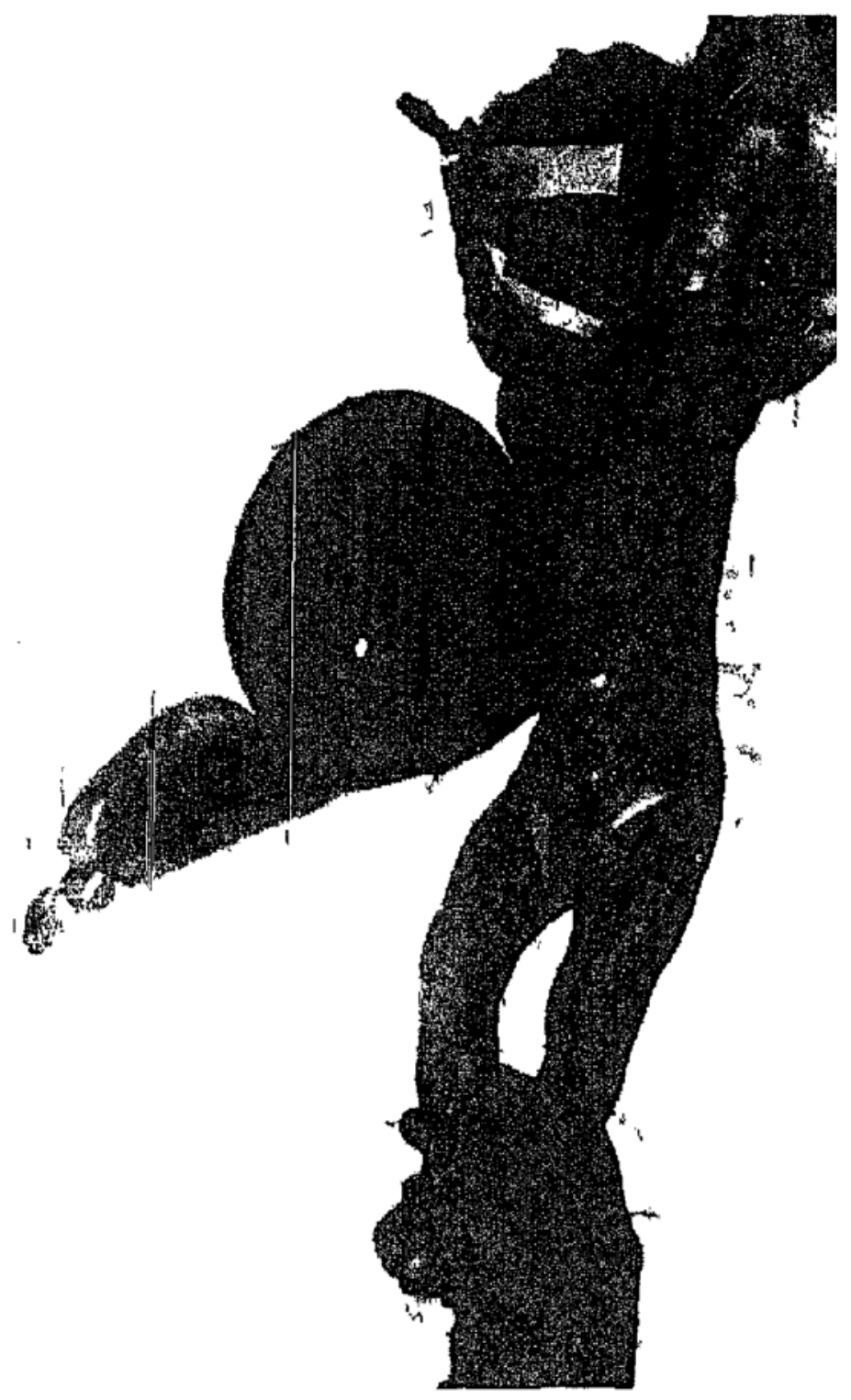

Ficune 7

Most paticnts come to sulgery quite early, not infiequently without an intid. venous infusion gong $A$ stomich tube should always be in place and the stomach e uefully emptied before unduction of andesthess if there is no nntia vonous infusion vunning the andestletist should attempt to cstablish a scalp win If this porcs difficult we sometmes resouto the use of intramuscular succun lcholune $1 \mathrm{mg} / \mathrm{lb}$ body werght after incluction with cyclopropane and hilotine Intubation con then easly be done after an interial of one to one and one half munutes idcal iclaration for sulgerv however is lacking unless the operation takes only about 10 muntas Anaesthesia his to be caned somewhal deeper peitoneal closue is less easv and recovery distunctly slower than with the use of intemittent intalvenous succmplchohne 
Extubation is done after careful stomach aspiration and suction, when the infant is awake; crying should be immediate. The total anaesthetic management of such cases has recently been well described."

\section{In the Older Child}

\section{Intussusception}

About 60 per cent of these are reduced by barium enema. The children who come to surgery are frightened by their experiencès in the Department of Radiology and generally should have an intravenous drip established before anaesthesia. Sometimes the intussusception will reduce spontaneously under anaesthesia. The manipulation of the bowel in attempted reduction is often said by surgeons to be shocking; this has not been observed with experienced surgeons and it may be due more to undue pulling on the omentum in the hands of the inexpert. If reduction is not possible in five minutes, then generally some more radical form of surgery is indicated; blood should then be given to the child, $10 \mathrm{ml} . / \mathrm{lb}$. body weight being generally regarded as a safe minimum.

\section{Appendectomy}

This is by far the commonest abdominal emergency in children. Diagnosis is usually early, dehydration uncommon, and the anaesthetist must establish his own intravenous needle. In these cases we induce the patient as described earlier, using a vein in the right antecubital fossa or on the hand for thiopental and succinylcholine. Spontaneous respiration is then allowed to return, the child being kept anaesthetized with halothane. This allows the anaesthetist a good opportunity to select the most suitable vein in the left arm, that is on the side away from the surgeon, by which intermittent succinylcholine can be given. Smaller children are best induced with cycloproplane and halothane. In chubby three or four year olds the veins on the dorsum of the feet are sometimes the best to be found, and should not be ignored.

The patient with a ruptured appendix and a generalized peritonitis of 'some days' standing is a different problem. Some surgeons favour conservative treatment; others wish to have the child anaesthetized in order to determine whether or not there is a fixed mass present in the right iliac fossa, which is regarded as contraindicating laparotomy; still others believe that laparotomy and appendectomy should be attempted anyway. There is no doubt that, if expertly managed, removal of the necrotic appendix and evacuation of the purulent peritoneal fluid leads to more rapid recovery. These patients are very ill; gastrointestinal suction and intravenous fluids are essential before operation. In addition to the normal daily water losses and the loss of fluid and electrolytes due to vomiting, diarrhoea, and gastrointestinal suction, there is the loss of fluid into the bowel itself to consider. Abdominal distension and loss of bowel sounds indicate that this problem must also be reckoned with. Complete correction of all deficits is not possible-nor practical. However, dehydration must be relieved, as shown by clinical signs and the disappearance of ketone bodies from the urine and lowering of the blood urea nitrogen towards normal, and losses of chloride, sodium, and potassium must at least partially be made up. Urinary output should rise towards normal. 
The anaesthetist will be very wary when he sees the distended abdomen. Vomiting and regurgitating during induction of or recovery from anaesthesia are potentially serious risks.

Meckel's Diverticulitis: Bleeding Meckel's Ulcer

The operative removal of a Meckel's diverticulitis poses no special problems. A bleeding ulcer in a Meckel's diverticulum can lead to a very severe degree of anaemia. Blood should be given preoperatively until the haemoglobin reaches at least $10 \mathrm{gm} \%$. More should be on hand for the operation itself.

\section{Abdominal Trauma}

These injuries are usually due to automobile accidents, the commionest ones at our hospital being ruptured spleen and perforation of the small bowel." When the spleen or liver has been damaged, other injuries will almost certainly- be found also, such as chest and head injuries, or fractures of the pelvis or long bones. Damage to the lung must be suspected with splenic rupture, even when no radiological evidence is seen; the presence of fractured ribs further sharpens one's suspicions. These accompanying lesions must be considered carefully; for example, faciomaxillary injuries cause distinct problems; a stove-in chest will indicate the need for tracheostomy, and intermittent positive pressure breathing; a fractured pelvis may mean a bladder full of blood, which will be unsuspected if a catheter is not passed. When a ruptured spleen is the only injury, the amount of blood loss is easy to underestimate; the peritoneal cavity of a five year old can accommodate a litre of blood without appearing more than mildly distended. Resuscitation is frequently inadequate: the temptation to use intravenous thiopental for induction through the readily available cut-down is best resisted in these circumstances. Once again, the use of intermittent succinylcholine with very light anaesthesila serves well.

\section{Indiyidual Choice of Technique}

The techniques described here have been evolved over a number of years. For example, during the four-year period 195.9-1962, there were 1136 emergency abdominal operations at our hospital, of which 195 or 17 per cent were done on infants. This experience is shared between a very small number of paediatric anaesthetists who work full-time at the Children's Hospital, Winnipeg. Those who work in other hospitals and in other clinical environments may well wish to develop and use techniques more applicable to their particular circumstances.

\section{SUMMARY}

The anaesthetist dealing with abdominal emergencies in children must take into account the condition of the child or infant, the environment of the hospital, which is quite different in the evening and at night from during the usual operating hours, and the skill of the operator as well as the surgical procedure.

Before surgery, the anaesthetist must assure himself that preparation is adequate. Infants will often require blood during the more complicated 
procedures. Good judgment is required to decide when the patient is in the best and safest condition for surgery and anaesthesia. The anaesthetist must be capable of assessing the total picture.

Induction of anaesthesia must be done most gently in the case of the extremely frightened child. Light anaesthesia, with controlled respiration and muscle relaxation, is the essence of a good technique. In this way respiratory and metabolic acidosis are avoided, better operating conditions are made available, and recovery is most rapid.

The danger of vomiting during all the stages of anaesthesia must be kept in mind. The endotracheal tube is not removed until every possible precaution has been taken to see that the stomach is empty and until the patient is as awake as possible.

Special problems are encountered in the new-born infant. His high body water content at birth and the fact that his total blood volume is so small make intravenous tluids unnecessary or dangerous; blood is needed, however, for most operations to cure congenital anomalies. Acid-base balance is unstable and the lungs and probably the kidneys are less efficient than in the adult. A technique of light anaesthesia with controlled respiration and muscle relaxation is especially desirable.

Diaphragmatic hernias and omphaloceles create special difficulties. Muscle relaxants are dangerous, but their cautious use may be essential to prevent excessive tissue damage. Long-standing pyloric stenosis demands very careful preparation, because of the compensated alkalotic state, usually accompanied by severe hypokalaemia.

Children with abdominal injuries sometimes have associated damage to the thoracic, cage, the lungs, the face and head, the pelvis and long bones. Blood loss may be far more than is suspected.

\section{RÉSUMÉ}

L'anesthésiste qui s'occupe des opérations abdominales pratiquées d'urgence chez les enfants, doit tenir compte de l'état de l'enfant ou du nouveau-né, des conditions de travail à l'hôpital, conditions moins favorables durant la nuit que durant les séances opératoires habituelles, de la dextérité de l'opérateur et de la technique chirurgicale.

Avant de commencer l'intervention, l'anesthésiste doit s'assurer que la préparation est adéquate. Les nouveaux-nés ont souvent besoin de transfusion de sang pendant les interventions les plus compliquées. Cela demande un bon jugement pour décider quand la condition du malade est la meilleure pour assurer le succès de la chirurgie et de l'anesthésie. L'anesthésiste doit être en mesure de parer à toute éventualité.

L'induction de l'anesthésie doit être faite avec douceur si l'enfant est très anxieux. Une anesthésie légère avec respiration contrôlée et un bon relâchement musculaire sont l'indice d'une bonne technique. Par cette méthode, l'acidose respiratoíre et métabolique est évitée, l'opération est facilitée et la guérison est plus rapide. 
Le danger de vomissement pendant toute la durée de l'anesthésie doit être présent à l'esprit. Le tube endotrachéal ne doit pas être retirié tant qu'on n'est pas certain que l'estomac soit vide; en outre, il faut attendre que le malade soit réveillé le plus possible.

On rencontre des problèmes spéciaux dans le cas du nouveau-né. Les liquides intraveineux deviennent inutiles et dangereux à cause du grand volume d'eau et du faible volume sanguin "à la naissance;' toutefois, il faut donner du sang dans la plupart des opérations pour anomalies congénitales. L'équilibre métabolique est instable; les poumons et probablement les reins fonctionnent moins bien que chez l'adulte. Une technique d'anesthésie légère avec respiration contrôlée et relâchement musculaire est spécialement désirable.

Les hernies diaphragmatiques et les omphalocèles créent des difficultés. Les myorésolutifs sont dangereux, malis leur usage prudent peut être essentiel pour prévenir des lésions profondes des 'tissus. Une sténose pylorique d'une durée prolongée demande une préparation prudente à cause de l'alcalose, généralement accompagnée d'une sévère hypopotassémie.

Les enfants souffrant de blessures abdominales ont parfois des dommages à la cage thoracique, aux poumons, au visage et à la tête, au bassin et aux os longs. La perte de sang peut êtrẹ plus importante qu'on ne le soupçonne.

\section{ACKNOWLEDGMENTS}

My thanks are due to Dr. C. C. Ferguson, Surgeon-in-Chief, The Children's Hóspital; Dr. S. Israels, Director, Department of Research and Clinical Investigation, The Children's Hospital; our Secretary, Mrs. E. Baird, and Mr. Tony Gibson, Medical Photographer, The Children's Hospital.

\section{REFERENCES}

1. McCaughey, T. J. The Muscle Relaxants in Infants and Children, Canad. Anaesth. Soc J 9:293 (1962).

2. Lehmann, H., Liddell, J, Blackwell, B.; O'Connor, D. C. J.; \& Daws, A. V. Two Further Serum Pseudocholinesterase Phenotypes as Causes of Suxamethonium Apnoea. Brit. Med. J. 1116 (April 27, 1963).

3. Brody, G. L. \& Sweet, R. B. Halothane Anesthesia as a Possible Cause of Massive Hepatic Necrosis. Anesthesiology 24:29 (1963).

4. Lindenbaum, J. \& Lemfer, E. Hepatic Necrosis Associated with Halothane Anesthesia. New Engl. J. Med. 268: 525 ( 1963 ).

5. Bunker, J. P. \& Blumenfeld, C. M. Liver Necrosis after Halothane Anaesthesia: Cause or Coincidence? New Engl. J. Med. 268: 531. (1963).

6. Conn, A. W. Anaesthesia for Pyloromyotomy in Infancy. Canad. Anaesth. Soc. J. 10: 18 (1963). 